\title{
Development and Validation of Stability-Indicating RP-HPLC Method for the Simultaneous Determination of Tizanidine HCl and Meloxicam in Rabbit's Plasma
}

\author{
Muhammad Zaman ${ }^{1,2}$, Muhammad Hanif ${ }^{1 *}$, Najm Ul Hassan Khan ${ }^{3}$, Asif Mahmood ${ }^{2}$, \\ Muhammad Naeem Qaisar ${ }^{4}$ and Huma $\mathrm{Ali}^{5}$ \\ ${ }^{1}$ Department of Pharmaceutics, Faculty of Pharmacy, Bahauddin Zakariya University, Multan, Pakistan \\ ${ }^{2}$ Department of Pharmaceutics, Faculty of Pharmacy, The University of Lahore, Lahore, Pakistan \\ ${ }^{3}$ Department of Pharmaceutical Chemistry, Faculty of Pharmacy, The University of Lahore, Lahore, Pakistan \\ ${ }^{4}$ College of Pharmacy, University of Sargodha, Sargodha, Pakistan \\ ${ }^{5}$ Department of Pharmaceutical Sciences, Jinnah Sindh Medical College University, Karachi, Pakistan
}

Received: 06 November 2017; accepted: 14 March 2018

\begin{abstract}
High-performance liquid chromatography (HPLC) is a widely used technique for the simultaneous detection and quantification of different drugs. The purpose of the current study was to develop a simple and cost-effective reversed-phase high-performance liquid chromatography (RP-HPLC) method for the simultaneous determination of tizanidine (TZN) $\mathrm{HCl}$ and meloxicam (MLX) in rabbit's plasma. Assay of TZN and MLX was performed after extraction of drug from plasma by liquid-liquid extraction technique using methanol and diethyl ether as protein precipitants. Isocratic elution was performed in a Kromasil ${ }^{\circledR} \mathrm{C} 18$ column (dimension, $250 \times 4.60 \mathrm{~mm}$; particle size, $5 \mu \mathrm{m}$ ) with mobile phase consisting of methanol-water (8:2). Orthophosphoric acid was used to adjust the $\mathrm{pH}$ of the mobile phase 3.0 , and detection was done at $228 \mathrm{~nm}$. Flow rate was $0.8 \mathrm{~mL} / \mathrm{min}$ with ambient temperature and average operating pressure of $1400 \mathrm{psig}$. Retention time of TZN was $2.612 \mathrm{~min}$ and that of MLX was $6.960 \mathrm{~min}$ with a resolution of 3.18. Both drugs showed satisfactory linearity in the range of 10 to $50 \mathrm{ng} / \mathrm{mL}$ with correlation coefficients $\left(R^{2}\right)$ of 0.9989 and 0.9972 for TZN and MLX, respectively. The developed method was validated successfully for linearity, system suitability, intra-day and inter-day accuracy, and precision, robustness, and specificity following International Conference on Harmonization ( $\mathrm{ICH}$ ) guidelines. Conclusively, a precise, stable, reproducible, economical, and suitable method for estimation of pharmacokinetic evaluation was developed and validated.
\end{abstract}

Keywords: Tizanidine $\mathrm{HCl}$, meloxicam, rabbit's plasma, method development, validation, simultaneous determination, RP-HPLC

\section{Introduction}

Tizanidine (TZN) is an associate imidazoline derivative used as potent muscle relaxant. It acts on centrally located $\alpha_{2}$ receptors for producing monolytic response on skeletal muscle [1]. It is a drug of choice in multiple sclerosis, spinal cord injury, and spasticity related pathologies. TZN is also used in different painful conditions like myofacial, refractory, neuropathic, and chronic tension associated pain. TZN is extensively absorbed across gastrointestinal tract (GIT). Peak plasma concentration is attained in 1 to $2 \mathrm{~h}$ after oral administration. It has $30 \%$ protein binding and undergoes extensive 1st pass metabolism. Chemically, it is [5-chloro-4-(2-imidazolin-2-ylamino)-2,1,3-benzothiadiazole] and demonstrates basic and lipophilic properties. Drug is ionized in acidic environment and is soluble in water. Meloxicam (MLX) is a nonsteroidal anti-inflammatory drug (NSAID) that has selective inhibitory effects on the inducible isoform of cyclooxygenase-2 [2]. Chemically, it is a 4-hydroxy-2-methyl$N$-(5-methyl-2-thiazolyl)-2H-1,2-benzothiazine-3-carboxamide-1,1dioxide. MLX is considered as an efficient choice in the treatment of rheumatoid arthritis and degenerative joint conditions in humans. Usually, administrated MLX is 1st metabolized to a 5'hydroxymethyl metabolite by CYP2C9 and CYP3A4; it is then metabolized to a 5'-carboxy metabolite. Oral absorption of MLX is about $89 \%$; however, poor water solubility limits its bioavailability. Many researchers reported a number of methods for determination of TZN in rabbit plasma. Similarly, several attempts

\footnotetext{
* Author for correspondence: Muhammadhanif14@yahoo.com; 0092-3336103668
}

have been exercised to develop a suitable and reproducible method for the determination of MLX alone as well as in combination with other drugs. However, no method is reported in the literature for the concurrent determination of TZN and MLX.

TZN and MLX were thought to be more effective when used in combination [3], so it is important to develop a method for quantification of both drugs simultaneously. In the present work, we have tried to develop a simple, economical, and reproducible method for the separation and quantification of TZN and MLX.

\section{Materials and Methods}

TZN and MLX were received as generous gift from Pharmedic Laboratories Lahore Pakistan, Orthophosphoric acid, chloroform, dichloromethane, and ethanol were purchased from SigmaAldrich, Germany. Diethyl ether, methanol, acetonitrile, sodium hydroxide, and dihydrogen potassium phosphate were obtained from Merck, Darmstadt, Germany. Double distilled water was freshly prepared in the research laboratory of Department of Pharmacy, Bahauddin Zakariya University, Multan, Pakistan. All the reagents and chemicals used were of high-performance liquid chromatography (HPLC) grade.

\section{Animals \\ Albino rabbits having an average weight of $3 \mathrm{~kg}$ were used in the study. They were kept in the environment with plenty of water and air. They were fed on standard chow diet com- posed of protein, carbohydrates, fats, fibers, and micronutri- ents with ad libitum water.}

This is an open-access article distributed under the terms of the Creative Commons Attribution-NonCommercial 4.0 International License (https://creativecommons.org/licenses/by-nc/4.0/), which permits unrestricted use, distribution, and reproduction in any medium for non-commercial purposes, provided the original author and source are credited, a link to the CC License is provided, and changes - if any - are indicated. 


\section{Instrumentation}

HPLC CTO-20A/20AC (Shamidzu, Japan), LC Solution Software-Schimadzu HPLC, Column Kromasil ${ }^{\circledR}$ C18 (250 mm $\times$ $4.6 \mathrm{~mm}$; particle size, $5 \mu \mathrm{m}$ ), and CTO-20A Column Oven (Shimadzu, Japan) were used for analytical process. Bench top $\mathrm{pH}$ meter with $25 \mathrm{CW}$ microprocessor (Bante Instruments, China) was used for $\mathrm{pH}$ measurement of the solutions. Materials were weighed by using weighing balance (JISICO J-HSD180 Korea), while hot plate magnetic stirrer (JISICO J-HSD180 Korea) was used in mixing and solution preparation. Sonication and centrifugation were performed by sonicator (DSA 100-SK1 Korea) and centrifuge machine (Heraeus, Osterode, Germany), respectively. Other instruments used in the project were as follows: vortex mixer (Whirl Mixer, England), filtration assembly (Sartorius, Gorringen, Germany), Swinney filter assembly (Millipore, England), Hamilton microliter syringe (Hamilton, Switzerland), micropipette (Mettler Toledo, Schwerzenbach, England), heparinized vacutainer (Becton Dickinson, Pakistan), and plastic syringes (1 cc, 5 cc, and $10 \mathrm{cc}$; Becton Dickinson, Pakistan).

\section{Method}

Preparation of Mobile Phase and Standard Solutions. Mobile phase was composed of a mixture of methanol and water in the ratio of $8: 2$ having $\mathrm{pH}$ at 3.0 adjusted by orthophosphoric acid and was prepared in volumetric flask.

Injection Volume and Sample Run Time. Twenty microliters of sample volume was injected, and run time was adjusted to 10 min after confirming that elution of both drugs is within $10 \mathrm{~min}$.

Wavelength of Detection. Detection wavelength was selected as $228 \mathrm{~nm}$ for simultaneous determination of TZN and MLX.

Flow Rate. The flow rate of mobile phase was $0.8 \mathrm{~mL} / \mathrm{min}$ at ambient temperature and 1400 psig column pressure.

Preparation of Stock Solutions and Working Standard. Both drugs, TZN and MLX, were equally weighed and dissolved in $50 \mathrm{~mL}$ methanol. A $1.0 \mu \mathrm{g} / \mathrm{mL}$ solution of drugs was taken as standard stock solution. Secondary stock solution of $100 \mathrm{ng} / \mathrm{mL}$ in plasma was prepared by spiking standard stock solution in $1.0 \mathrm{~mL}$ of blank plasma, which was further used for the preparation of solutions $10,20,30,40$, and $50 \mathrm{ng} / \mathrm{mL}$ concentrations by serial dilution [1].

Determination of TZN and MLX in Rabbit Plasma. Commonly used liquid-liquid extraction method was adapted for the extraction of TZN HCl and MLX from the plasma [4]. Five milliliters of methanol was added into plasma, vortexed for $10 \mathrm{~min}$ to ensure proper mixing, and centrifuged for $20 \mathrm{~min}$ at $5000 \mathrm{rpm}$. Supernatant was carefully transferred to another test tube and was dried by using light stream of nitrogen at $40{ }^{\circ} \mathrm{C}$. Dried sample was reconstituted in $200 \mu \mathrm{L}$ of mobile phase, then vortexed for $2 \mathrm{~min}$, and recentrifuged for $5 \mathrm{~min}$ at $5000 \mathrm{rpm}$. Twenty microliters of the ultimate sample was taken, filtered through syringe filter (Sartorius, $0.22 \mu \mathrm{m}$ ), and injected into the HPLC system via injection loop for analysis.

Validation of the Developed Method. Validation of the developed method was carried out as per International Conference on Harmonization ( $\mathrm{ICH})$ guidelines analyzing different parameters, i.e., linearity, precision, accuracy, specificity, system suitability, and robustness [5, 6].

Linearity and Calibration Curves. Linearity was evaluated and determined between different concentrations in the range of 10 to $50 \mathrm{ng} / \mathrm{mL}$. Samples were analyzed in triplicate, and calibration curve was constructed by taking concentrations at $x$ axis and peak area on $y$ axis, and coefficient of correlation $\left(R^{2}\right)$ was determined by applying straight line equation [7, 8].

System Suitability. System suitability was demonstrated by injecting half-dozen injections containing $2 \mathrm{ng} / \mathrm{mL}$ of each
TZN and MLX. Continual injections were used to assess the system suitability on every day of method validation, and features including percent relative standard deviation (\%RSD), tailing factor, and theoretical plate were calculated.

Intra-Day and Inter-Day Precision. Five samples of three different concentrations, i.e., 2, 6, and $10 \mathrm{ng} / \mathrm{mL}$, in plasma were analyzed at different time in the same day for inter-day precision determination and analyzed for three consecutive days for intraday precision. Concentrations were calculated using standard calibration curves [9, 10].

Robustness. Capacity of the developed method to remain unaffected by minor variation in the chromatographic conditions such as flow rate and organic contents in mobile phase was determined [11]. It was done by injecting sample under set conditions, and assay of TZN and MLX was performed [12].

Accuracy. Recovery studies were conducted to find out the accuracy of the method, and it was established by comparative study of drug spiked in plasma and in mobile phase [13]. Three different concentrations $(10,20$, and $30 \mathrm{ng} / \mathrm{mL})$, each with 5 replicates, were examined for determination of recovery [14].

Specificity. In order to confirm that the developed method was specific, interventions of other components including mobile phase and plasma were detected, and for this purpose, repeated injections of mobile phase, plasma, and drug samples were injected [15].

Limit of Quantification and Limit of Detection. Limit of quantification (LOQ) and limit of detection (LOD) were established by analysis of different concentrations $(0.50,1.0,5$, 7.5 , and $10 \mathrm{ng} / \mathrm{mL}$ ). They were determined by using signal-tonoise ratio of $3: 1$ and 10:1 $[16,17]$. Mathematically,

$$
\begin{gathered}
\mathrm{LOD}=3 O^{*} / \mathrm{S} \\
\mathrm{LOQ}=10 O^{\prime} / S .
\end{gathered}
$$

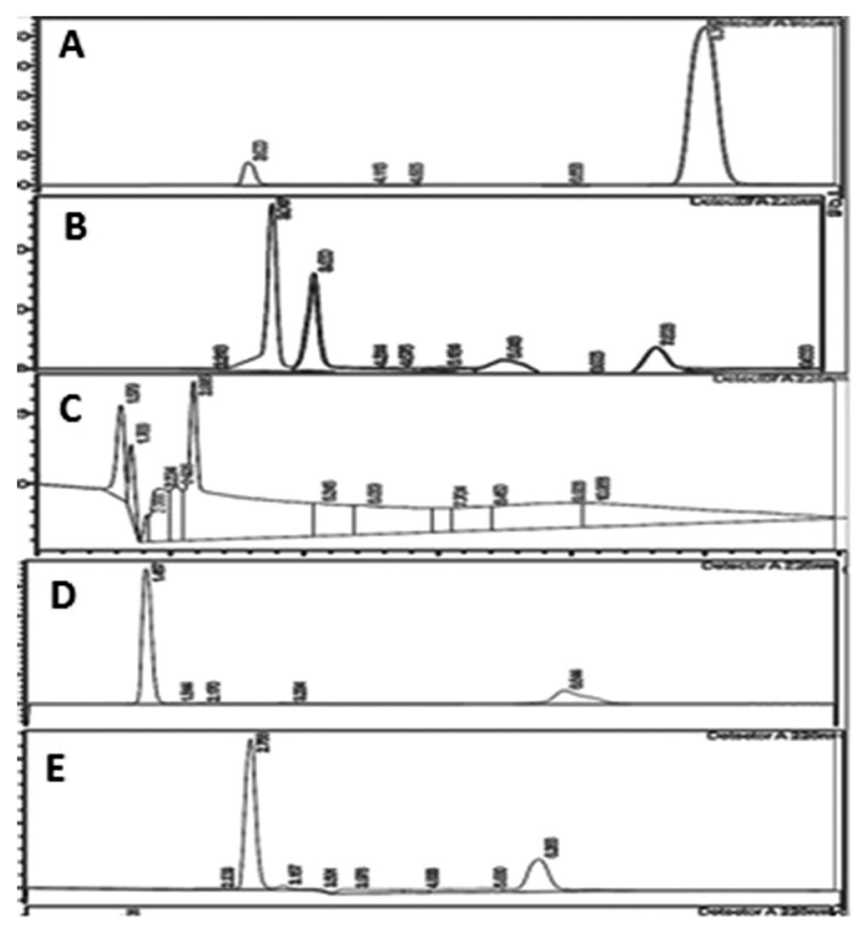

Figure 1. HPLC chromatograms at different chromatographic conditions used for method development. Peaks of TZN HCl and MLX when $\mathrm{pH}$ of mobile phase was 5.0. (A), Peaks of drugs when $\mathrm{pH}$ of mobile phase was below 3.0. (B), Eluted peaks of drugs at changed mobile phase composition (C), Peaks, when flow rate was reduced from $0.8 \mathrm{ml} / \mathrm{min}$ (D), Peaks, when flow rate was greater than $0.8 \mathrm{ml} / \mathrm{min}(\mathrm{E})$ 
TZN HCl

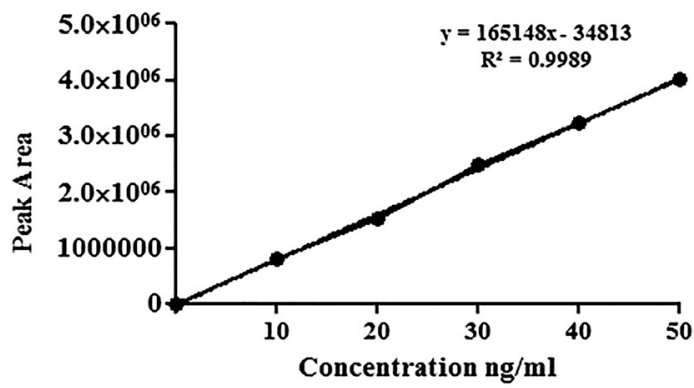

MILX

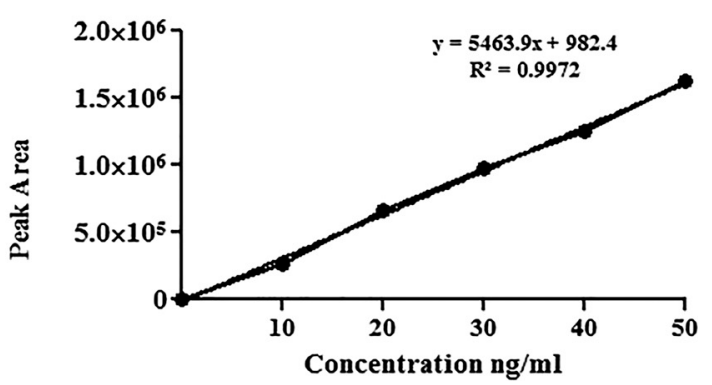

Figure 2. Calibration curves of TZN HCl and MLX showing linearity in the concentration range of 10 to $50 \mathrm{ng} / \mathrm{mL}$ of rabbit plasma

Plasma Stability Study of the Drugs. Freeze and thaw method was used for the stability analysis of plasma, containing drugs $[5,18,19]$. This stability study was evaluated with two concentrations levels, i.e., low $(10 \mathrm{ng} / \mathrm{mL})$ and high $(50 \mathrm{ng} / \mathrm{mL})$ concentrations, each having 15 samples. Samples were made frozen at a temperature of about $-20{ }^{\circ} \mathrm{C}$ for $24 \mathrm{~h}$. Then, a set of the samples was defrozen and analyzed while the rest of the samples were kept frozen for the remaining $24 \mathrm{~h}$. Other two cycles of the studies were subjected to the same procedure to complete the stability studies [20]. A comparison of these samples was done with the freshly prepared samples.

\section{Results and Discussions}

The need was to develop and validate a method in rabbit's plasma to assure its effectiveness in in vivo pharmacokinetic studies of TZN and MLX after administration of prepared buccal films to the rabbits. Feasibility of different solvent systems methanol-water, acetonitrile-water, and acetonitrile-phosphate buffer in different compositions, pumped at different flow rates (in the range of $0.5-1.5 \mathrm{~mL} / \mathrm{min}$ ) having variable $\mathrm{pH}$ range (2.0-7.0) and at different column oven temperatures (in the range of $25-40{ }^{\circ} \mathrm{C}$ ) was evaluated. Different retention times and peak behaviors were recorded (Figure 1). The best results were obtained using methanol-water in the ratio of 80:20, v/v ( $\mathrm{pH}$ adjusted to 3.0 with orthophosphoric acid at a flow rate of $0.8 \mathrm{~mL} / \mathrm{min}$ ). While optimizing the composition of mobile phase, $\mathrm{pH}$ was fixed to 3.0, and while assessing the effect of $\mathrm{pH}$ of mobile phase, the composition of mobile phase was fixed as methanol-water $(80: 20, \mathrm{v} / \mathrm{v})$. Retention times of all analytes were variable at different $\mathrm{pH}$ values, composition of mobile phase, and flow rates. When $\mathrm{pH}$ of mobile phase was decreased from 7.0, the retention times of analytes were very short, but when $\mathrm{pH}$ was gradually decreased, the retention times were found increasing. Below $\mathrm{pH} 3.0$, the retention times increased but symmetry of the peaks was disturbed. At pH 3.0, sharp peaks with good symmetry and reasonable retention times were obtained. Similarly, when compositions and flow rates of the mobile phase were changed, different peak behaviors were recorded. However, the best results were obtained with the mobile phase composition methanol-water $(80: 20, \mathrm{v} / \mathrm{v})$ and flow rate of $0.8 \mathrm{~mL} / \mathrm{min}$. TZN is a basic compound, and MLX has acidic and basic groups. Change of mobile phase $\mathrm{pH}$ caused a change in the ionization of these analytes and in the retention behavior. Various detection wavelengths in the ultraviolet (UV) range of 220-365 $\mathrm{nm}$ were tried for monitoring of all analytes. Keeping in view the theoretical values of molar absorptivity coefficient of TZN and MLX, the wavelength $228 \mathrm{~nm}$ was selected as the optimum wavelength for separation, detection, and determination of TZN and MLX. Five different types of columns were used to find better separation of drug. While selecting the best column for analysis, all other parameters were kept constant. Kromasil ${ }^{\circledR}$ C18 (HPLC column; $250 \mathrm{~mm} \times 4.6 \mathrm{~mm}$; particle size, $5 \mu \mathrm{m}$ ) was selected for HPLC analysis of TZN and MLX in this study.

Method Development in Rabbit Plasma. The experimental conditions such as mobile phase having the composition of methanol-water in the ratio of 80:20 (v/v), $\mathrm{pH}$ adjusted to 3.0, flow rate of $0.8 \mathrm{~mL} / \mathrm{min}$, ambient temperature, and column Kromasil $^{\circledR}$ C18 (250 mm $\times 4.6 \mathrm{~mm}, 5 \mu \mathrm{m}$ particle size $)$ were

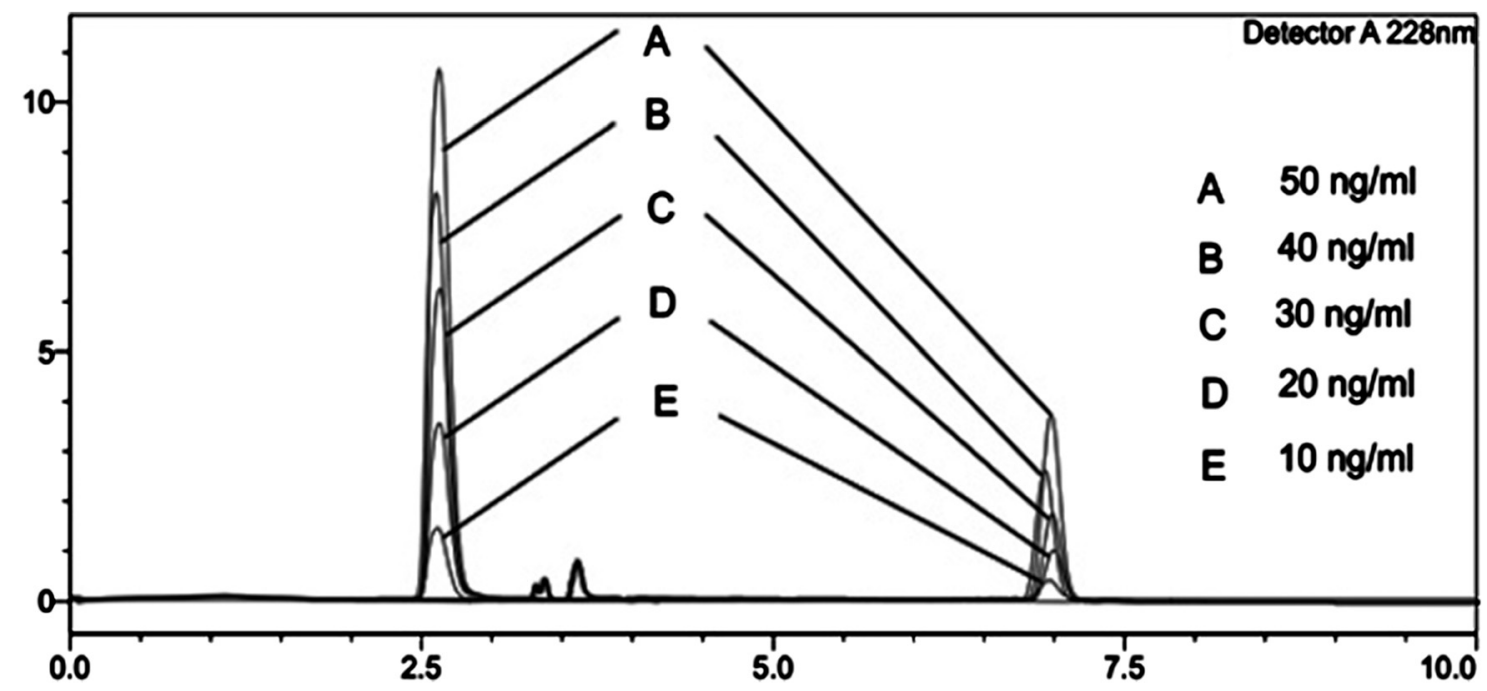

Figure 3. Overlay chromatograms showing linearity of $\mathrm{TZN} \mathrm{HCl}$ and $\mathrm{MLX}$ in rabbit's plasma in the concentration range of $10 \mathrm{ng} / \mathrm{mL}$ to $50 \mathrm{ng} / \mathrm{mL}$ 
$<$ Chinromatogram>

$\mathrm{mW}$

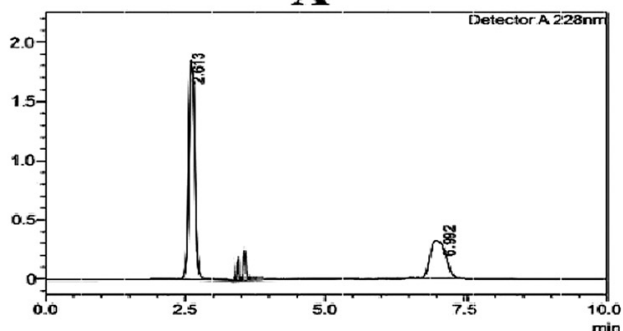

$<C$ ihromatograim $>$

B

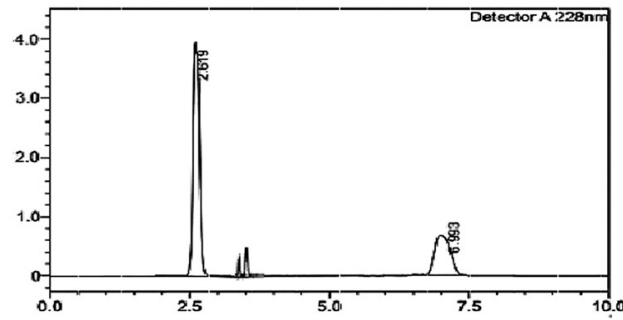

$\mathrm{mv}$

hromatogram

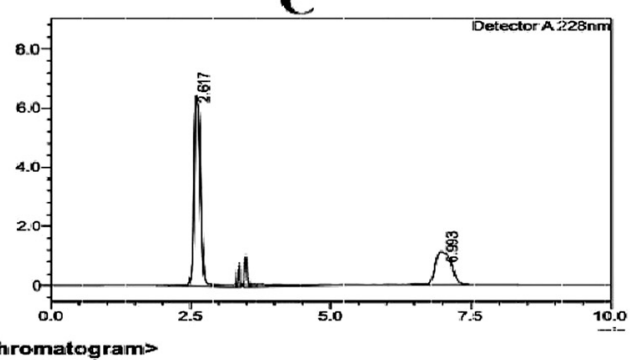

$<$ Chromatograim>

$\mathrm{m} \times$

D

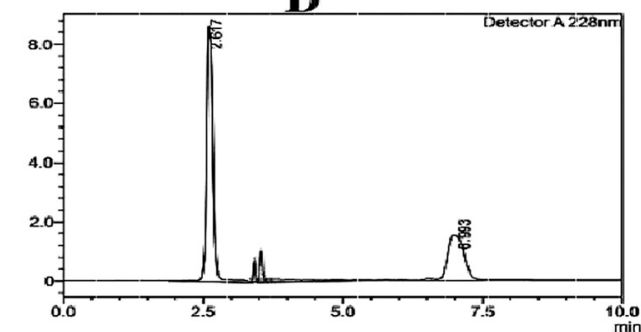

$<\mathrm{C}$

$\mathbf{E}$

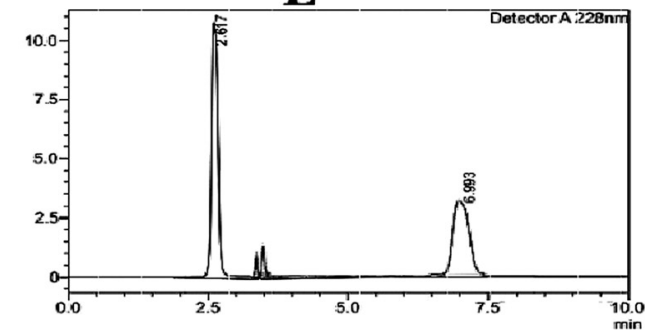

Figure 4. HPLC chromatogram showing linearity of drugs in rabbit's plasma. $\mathrm{A}=$ spiked plasma with $10 \mathrm{ng} / \mathrm{ml}$ of drugs, $\mathrm{B}=$ spiked plasma with $20 \mathrm{ng} / \mathrm{ml}$ of drugs, $\mathrm{C}=$ spiked plasma with $30 \mathrm{ng} / \mathrm{ml}$ of drugs, $\mathrm{D}=$ spiked plasma with $40 \mathrm{ng} / \mathrm{ml}$ of drugs and $\mathrm{E}=$ spiked plasma with $50 \mathrm{ng} / \mathrm{ml}$ of drugs

selected for quantification of TZN and MLX. The retention time of TZN was $2.612 \mathrm{~min}$ and that of MLX was $6.960 \mathrm{~min}$ with a resolution of 2.98 .

Validation of the Developed Method

Linearity (Calibration Curve). Both drugs were separated successfully with good resolution and reasonable retention times.
Retention time was $2.612 \mathrm{~min}$ and $6.960 \mathrm{~min}$ for TZN and MLX, respectively. Linearity of both drugs was assessed between the concentration ranges from 10 to $50 \mathrm{ng} / \mathrm{mL}$. Both drugs showed considerable linearity with coefficient of correlation $\left(R^{2}\right)$ of 0.998 for TZN and 0.997 for MLX (Figures 2, 3, and 4). Qi et al. in 2003 have developed a method for the isocratic determination of TZN HCl, and Vignaduzzo et al. in 2008, for MLX, using HPLC and reported the linearity with $R^{2}$ of 0.9998 and 0.9989 , respectively. There were minor differences in the value of $R^{2}$, which may be due to the range difference selected for evaluation of linearity behavior [21, 22].

System Suitability Test. Suitability studies revealed that the studied parameters were satisfactory and peaks of both drugs showed good resolution with low \%RSD (Table 1). System suitability is an important indicator of validated method. Shaji and Varkey have developed and validated the method for determination of MLX using piroxicam as an internal standard in human plasma. They have calculated tailing factor, retention time, resolution, and symmetry of the eluted peaks. The reported retention time was 6.9 min which was conceding with the determined retention time of the current study for MLX; however, currently reported results of other studied parameters were better [23]. Similarly, Puranik et al. have developed a method for simultaneous determination of TZN and valdecoxib and their finding for system suitability studies was similar to the findings of this project [24].

Intra-Day and Inter-Day Precision. The method was found to be accurate and precise, when studies were conducted for analysis. $\% \mathrm{RSD}$ was in the range of $0.44 \%$ to $1.19 \%$ and $0.51 \%$ to $1.20 \%$ for intra-day and inter-day, respectively, declaring that the developed method was well within the acceptance criteria (Table 2) [25]. From the results, it was concluded that the method would be applicable and useful for the analysis and simultaneous determination of both TZN and MLX in animal models. Kaul et al. have developed a method for simultaneous determination of TZN and rofecoxib, and they have found the developed method accurate and precise as well as obtained comparable results with current studies [26].

Robustness. The developed method was found to be stable under minor variation in flow rate and mobile phase compositions. Minor deliberate changes in different experimental parameters such as flow rate $( \pm 5 \%)$ and methanolic contents of mobile phase ( \pm 0.2 units) did not significantly affect the recoveries, peak area, and retention time, indicating that the proposed method was robust. Chandra et al. in 2012 and Bandarkar et al. in 2009 reported the validity of their developed method. From the outcomes of the studies, they concluded that the developed method was robust and suitable for determination of TZN and MLX from spiked plasma as well as from prepared samples to study pharmacokinetics [27, 28].

Accuracy. Accuracy of the method was determined in terms of recovery studies and declared acceptable by falling in the criteria of $98 \%$ to $102 \%$ [26]. The method was found to be accurate, providing a high percentage of drug recoveries of both TZN $(98.88 \%, 99.85 \%$, and $99.86 \%)$ and MLX $(99.84 \%, 98.17 \%$, and $97.44 \%$ ) for selected samples of 10,30 , and $50 \mathrm{ng} / \mathrm{mL}$ solutions (Table 3). Similar results of recovery studies were obtained by Siddiqui in 2001 and Velpandian et al. in 2000 for TZN HCl and MLX in their studies respectively [29, 30].

Specificity. Specificity of the developed method for the quantification and pharmacokinetics of drugs is very essential, as

Table 1. System suitability studies for developed method and values of calculated theoretical plate, tailing factor, resolution and retention times

\begin{tabular}{lccccc}
\hline Drugs & Mean & \%RSD & Theoretical plates & Tailing factor & Resolution \\
TZN HCl & 11,548 & 0.0916 & 2298 & 1.03 & 2.01 \\
MLX & 8287 & 0.0978 & 3612 & 0.87 & 3.18 \\
USP recommendation & & $<2$ & $>2000$ & 0.8 to 1.5 & 6.960 \\
\hline
\end{tabular}


Table 2. Intra-day and inter-day accuracy and precision

\begin{tabular}{|c|c|c|c|c|c|}
\hline \multirow[t]{2}{*}{ Drugs } & \multirow[t]{2}{*}{ Actual amount } & \multicolumn{4}{|c|}{ Concentration found } \\
\hline & & Intra-day $($ mean $\pm \mathrm{SD})$ & $\%$ RSD & Inter-day (mean \pm SD) & $\%$ RSD \\
\hline \multirow[t]{3}{*}{$\mathrm{TZN} \mathrm{HCl}$} & 2 & 1.977 & 1.139 & 1.912 & 0.96 \\
\hline & 6 & 5.991 & 0.784 & 5.891 & 1.01 \\
\hline & 10 & 9.986 & 0.102 & 9.843 & 1.2 \\
\hline \multirow[t]{3}{*}{ MLX } & 2 & 1.996 & 0.637 & 1.911 & 0.85 \\
\hline & 6 & 5.890 & 1.197 & 5.831 & 0.92 \\
\hline & 10 & 9.744 & 0.444 & 9.721 & 0.51 \\
\hline
\end{tabular}

Table 3. Recovery studies of TZN HCl and MLX after repeated injection $(n=6)$ of known concentrations of drugs

\begin{tabular}{lcccc}
\hline Drugs & $\begin{array}{c}\text { Concentration } \\
(\mathrm{ng} / \mathrm{mL})\end{array}$ & $\begin{array}{c}\text { Amount } \\
\text { recovered }\end{array}$ & \% Recovery & \%RSD \\
\hline TZN HCl & 10 & 9.88 & 98.88 & 1.13 \\
& 30 & 29.95 & 99.85 & 0.78 \\
MLX & 50 & 49.93 & 99.86 & 0.10 \\
& 10 & 9.98 & 99.84 & 0.63 \\
& 30 & 29.45 & 98.17 & 1.19 \\
& 50 & 48.72 & 97.44 & 0.44 \\
\hline
\end{tabular}

interruption of any excipients can effect the findings of the compound under observation. Bae et al. in 2007 have developed a method in human plasma for pharmacokinetic evaluation of MLX and found it specific for the selected drug [31]. Similarly, Ali et al. in 2014 have done specificity studies for their developed method in human plasma and found it specific for TZN, as the method developed in the current studies was found specific for MLX and TZN [1]. The developed method showed good selectivity as no peak was detected at the retention times of both drugs as illustrated in Figure 5.

LOD and $\mathbf{L O Q}$. LOD and LOQ were also determined, and for this purpose, samples having different concentration ranges were analyzed by injecting 5 replicates of each injection. For $\mathrm{TZN}$, the minimum detectable quantity was about $0.50 \mathrm{ng} / \mathrm{mL}$ and the minimum quantifiable amount was about $1.0 \mathrm{ng} / \mathrm{mL}$, and for MLX, LOD and LOQ were approximately 3.0 and $4.0 \mathrm{ng} / \mathrm{mL}$, respectively. Results were comparable to those obtained by Ali and his coworkers in 2014 for determination of TZN in rabbits plasma; however, the developed method showed better sensitivity for MLX as compared to those studied by Hanif et al. in 2011 [1, 32].
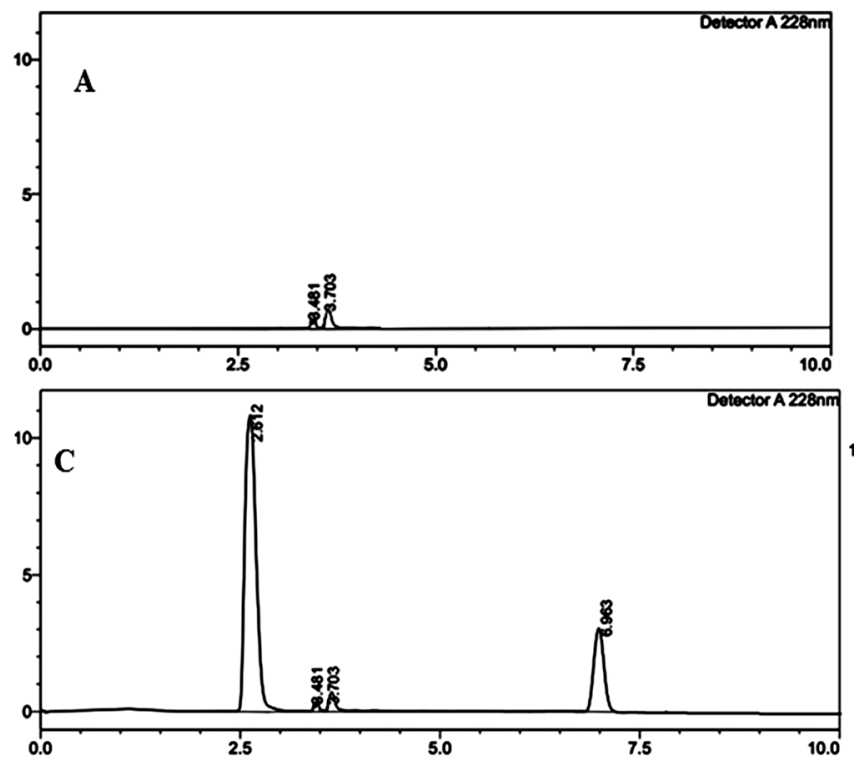

Stability Studies of the Drug Containing Plasma. Three freeze-thaw cycles of the stability studies were performed, and it was observed that samples had remained quite stable for the selected duration of stability studies. Samples of lower concentrations have shown $98.32 \%, 97.47 \%$, and $98.13 \%$ for TZN and 97.11\%, 99.39\%, and 98.1\% for MLX, while samples of high concentrations have shown accuracy of $98.09 \%, 97.99 \%$, and $98.41 \%$ for TZN and $98.63 \%, 97.89 \%$, and $97.83 \%$ for MLX for cycles 1,2 , and 3 , respectively. In the three freeze-thaw cycles, the average degradation was found to be less than $3 \%$ for selected lower and high concentrations of the drugs. Bae et al. in 2007 and Kukes et al. in 2016 have reported the plasma stability studies of MLX and TZN after performing freeze-thaw stability studies $[19,31]$ indicating the suitability of the selected method for plasma stability of the drugs.

\section{Conclusion}

The goal of the study was to develop a suitable method for the simultaneous determination of TZN and MLX in blood plasma. Attempt was successful as a suitable method was not only developed but also validated successfully. All the parameters such as linearity, accuracy, intra-day and inter-day precision, and robustness were successfully validated and found to be fallen in the range of acceptance criteria. In a nutshell, the method is useful for the detection of TZN and MLX in blood plasma.

\section{Compliance with Ethical Standard}

All procedures performed in the current studies involving animals were in accordance with the ethical standards of the institutional research committee. All animal experiments were approved by the instructional animal research ethic committee of

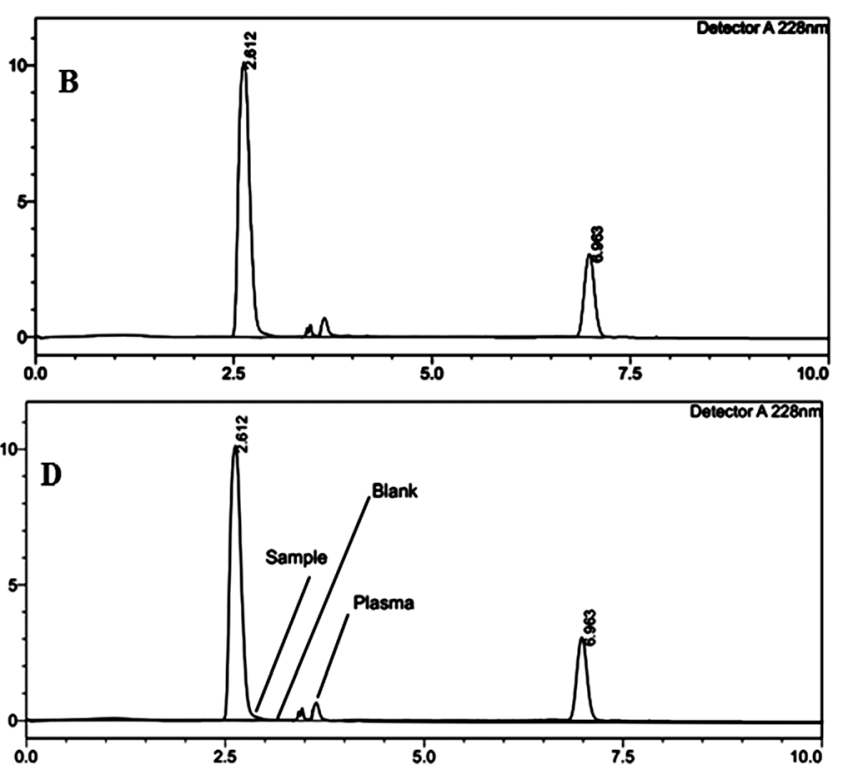

Figure 5. Pictorial illustration for specificity of the developed method for TZN HCl and MLX HPLC chromatogram of blanked plasma (A), HPLC chromatogram of plasma spiked with TZN HCl and MLX (B), HPLC chromatogram of drugs samples taken from rabbits after administration of buccal films (C), and overlay chromatograms of blank plasma (D), sample showing specificity of the method 
the Faculty of Pharmacy, The University of Lahore, void ref. no. "IAEC-2016-18."

\section{Acknowledgment}

The authors are thankful to the Higher Education Commission (HEC) of Pakistan, as well as the faculty and laboratory staff of Faculty of Pharmacy, The University of Lahore, for their kind support to complete the current project successfully.

\section{Conflict of Interest}

The authors have nothing to disclose, and they are willing to submit the article in the journal.

\section{References}

1. Ali, T.; Shoaib, M. H.; Yousuf, R. I.; Siddiqui, F.; Ali, H.; Ahmed, F. R.; et al. Afr. J. Pharm. Pharmacol. 2014, 8, 199-205.

2. Wright, T. L.; Eshar, D.; McCullough, C.; Warner, M.; Kukanich, B. J. Am. Assoc. Lab. Anim. Sci. 2017, 56, 539-543.

3. Jain, N. K.; Kulkarni, S. K.; Singh, A. Life Sci. 2002, 70, 2857-2869.

4. Labat, L.; Goncalves, A.; Marques, A. R.; Duretz, B.; Granger, B.; Declèves, X. Biomed. Chromatogr. 2017.

5. Engla, G.; Soni, L.; Dixit, V. Int. J. Pharm. Life Sci. 2016, 7.

6. Guideline IHT. Validation of Analytical Procedures: Text and Methodology Q2 (R1)(2005). http://www ich org/cache/compo/363-272-1 html. 2010, 1-17.

7. Fuster, J.; Negro, S.; Salama, A.; Fernández-Carballido, A.; Marcianes, P.; Boeva, L.; et al. Int. J. Pharm. 2015, 491, 310-7.

8. Segundo, M. A.; Abreu, V. L.; Osório, M. V.; Nogueira, S.; Lin, P. K. T.; Cordeiro-da-Silva, A.; et al. J. Pharm. Biomed. Anal. 2016, 120, 290-296.

9. Jain, H. K.; Pethkar, S. World J. Pharm. Pharm. Sci. 2016, 5, 1452-1459.

10. Șenkardeș, S.; Özaydın, T.; Uğurlu, T.; Küçükgüzel, Ș. G. Marmara Pharm. J. 2017, 21.
11. Ganorkar, S. B.; Dhumal, D. M.; Shirkhedkar, A. A. Arabian J. Chem. 2014, 10, 360-367.

12. Lu, C.; Jia, Y.; Yang, J.; Jin, X.; Song, Y.; Liu, W.; et al. Acta Pharm. Sin. B 2012, 2, 205-212.

13. Karan, S.; Pal, R.; Ruhidas, B.; Banerjee, S.; Chatterjee, T. K. Indian J. Pharm. Ed. Res. 2016, 50, 442-450.

14. Kumar, S.; Lather, V.; Pandita, D. Food Chem. 2016, 197, 959-964.

15. Hanif, M.; Nazir, N.; Zia, M. U.; Chudhary, B. A.; Abbas, G.; Rana, S. J.; et al. Am. J. Pharm. 2015, 34, 1737-1742.

16. Mir, K. B.; Khan, N. A. World J. Pharm. Pharm. Sci. 2016, 2, 1447-1456.

17. Shin, C.; Jang, H.; Jo, H.; Kim, H.-J.; Kim, D.-S.; Hong, J.-H. Food Control 2017, 77, 171-178.

18. Muralidharan, S.; Kumar, J.; Vijayan, V. Pharmacol. Toxicol. Biomed. Rep. 2016, 2, 52-55.

19. Kukes, V.; Reikhart, D.; Artnautov, V.; Torshina, E.; Kapashin, A.; Belostotskii, A. Pharm. Chem. J. 2016, 50, 394-403.

20. Bakhtiar, R.; Lohne, J.; Ramos, L.; Khemani, L.; Hayes, M.; Tse, F. J. Chromatogr. B 2002, 768, 325-340.

21. Qi, M.-L.; Wang, P.; Wang, L. Anal. Chim. Acta 2003, 478, 171-177.

22. Vignaduzzo, S. E.; Castellano, P. M.; Kaufman, T. S. J. Pharm. Biomed. Anal. 2008, 46, 219-225.

23. Shaji, J.; Varkey, D. Int. J. Pharm. Sci. Rev. Res. 2012, 12, 152-160.

24. Puranik, M.; Wadher, S.; Dhole, S.; Yeole, P. Indian J. Pharm. Sci. 2006, 68 .

25. Nirogi, R. V.; Kandikere, V. N.; Shukla, M.; Mudigonda, K.; Maurya, S. Rapid Commun. Mass Spectrom. 2006, 20, 2286-2292.

26. Kaul, N.; Dhaneshwar, S.; Agrawal, H.; Kakad, A.; Patil, B. J. Pharm. Biomed. Anal. 2005, 37, 27-38.

27. Chandra, P.; Rathore, A. S.; Lohidasan, S.; Mahadik, K. R Sci. Pharm. 2012, 80, 337-352.

28. Bandarkar, F. S.; Vavia, P. R. Trop. J. Pharm. Res. 2009, 8.

29. Siddiqui, F. A.; Arayne, M. S.; Sultana, N.; Qureshi, F. J. AOAC Int. 2011, $94,150-158$.

30. Velpandian, T.; Jaiswal, J.; Bhardwaj, R. K.; Gupta, S. K. J. Chromatogr. B: Biomed. Sci. Appl. 2000, 738, 431-436.

31. Bae, J.-W.; Kim, M.-J.; Jang, C.-G.; Lee, S.-Y. J. Chromatogr. B 2007, $859,69-73$

32. Hanif, M.; Shoaib, M. H.; Yousuf, R. I.; Khan, A.; Anwer, S.; Rasul, A.; Sattar, S. Afr. J. Pharm. Pharmacol. 2011, 5, 2342-2348. 